from 'pre-diabetic' cats. The blood-sugar level of recipient rats was not significantly influenced by pancreatico-duodenal blood from the refractory cat, nor by peripheral blood from the cat with metahypophyseal diabetes.

Discussion. The results indicate that portal blood but not peripheral blood of animals made diabetic by growth hormone exerts a hyperglyc:emic effect on recipient ADHA rats. Peripheral blood, on the other hand, sometimes causes a significant fall in the blood-sugar level of recipient ADHA rats such as might indicate the presence of insulin. These results are consistent with the view that growthhormone treatment causes the liberation of the hyperglycæmic substance from the pancreatic islets, and that this substance, in contrast with insulin, does not reach the peripheral veins in appreciable amounts.

It must be admitted that other interpretations of these results are not ruled out by the present experiments. Since, however, pancreatico-duodenal or portal vein blood from suitable animals treated with growth hormone exerts a hyperglycæmic action in ADHA rats, the simplest hypothesis, namely, that this effect is due to the presence in portal blood of the hyperglycæmic substance from pancreatic islets, may be accepted until evidence disproving it is obtained.

We do not wish to discuss here the possibility that the influence of growth hormone on carbohydrate metabolism is mediated in part or wholly by secretion of the pancreatic hyperglycæmic factor. We do wish to point out, however, that since the factor is not confined to the pancreatic islets ${ }^{7}$, experiments demonstrating an action of growth hormone on the carbohydrate metabolism of completely depancreatized animals ${ }^{\bullet}$ do not finally exclude this possibility.

Surrmary. Pituitary growth hormone was given to alloxan-diabetic-hypophysectomized-adrenalectomized rats, or to intact cats under conditions such that diabetes was induced. Portal blood from these animals was consistently found to exert a hyperglycœmic action when administered to recipient alloxan-diabetic-hypophysectomized-adrenalectomized rats. Such a hyperglycæmic effect was not found when growth hormone was administered directly to the recipient rats. These observations are consistent with the view that under the influence of growth hormone the pancreatic islets liberate their contained hyperglycæmic substance into the portal blood.

We are grateful for the technical assistance we received, particularly from Mr. M. Snowdon, and for financial assistance given by the Medical Research Council to one of us (F. G. Y.) and by Boots Pure Drug Co., Ltd., to another (J. B.).

${ }^{1}$ Bornstein, J., Austral J. Exp. Biol. Med. Sci., 28, 87 (1950); cf. Anderson, E., I

${ }^{2}$ Cotes, P. M., Reid, E., and Young, F. G., Nature, 164, 209 (1949). Canpbell, J., Davidson, W. F., Stair, W. D., and Lei, H. F. Endocrin., 46, 273

3 Houssay, B. A., and Anderson, E., Endocrin., 45, 627 (1949).

- Bornstein, J., J. Endocrin. (in the press).

- Marks, H. P., and Young, F. G., J. Endocrin., 1, 470 (1939).

- Thorognod, E., and Zimmermann, B., Endorrin., 37, 191 (1945)

${ }^{7}$ Sutherland, E. W., and de Duve, C., J. Biol. Chem., 175, 663 (1948). ${ }^{8}$ cf. Li, C. H., Evans, H. M., and Simpson, M. E., J. Biol. Chom.', J. A., J. Biol. Chem, 176, $735(1948)$; modiffeations to these prof. C. H. Li and Prof. A. E. Wilhelmi.

- Milman, A. E., de Moor, P., and Lukens, F. D. W., Amer. J. Physiol., 166,354 (1951).

\section{LONGEVITY OF NELUMBO FRUITS}

CONSIDERABLE interest was aroused in Great 4 Britain in 1933 by the flowering at the Royal Botanic Gardens, Kew, of plants of the sacred lotus (Nelurrbo nucifera Gaertner, syn. Nelumbium speciosum Willd.) raised from fruits taken there by a Japanese botanist, Ichiro Ohga, who had found them in the peat of a long-dried-up Manchurian lake (Bot. Mag. '1 okyo, 37, 87; 1923).

A like interest has been aroused this year in the United States by the germination at Washington in March 1951 of Nelumbo fruits having the same origin. These fruits came from a peat layer overlaid by several feet of loess on which trees grew; hence Ohga concluded that they must be at least $300-400$ years old. Nelumbo fruits are nut-like and commonly regarded as seeds, the apparent fruit being a large obconical receptacle; they have a very hard coat impervious to air and water, and will not germinate until this coat has been broken or softened, for example, by filing or by the use of concentrated sulphuric acid. Fruits known to be 150 years old were germinated by Robert Brown; others known to be fifty-six years old were germinated by Becquerel (see Kew Bulletin, 263; 1933). An interesting paper on "How old are the Manchurian Lotus Seeds?" by Prof. Ralph W. Chaney, Department of Paleontology, University of California, indicates that these Manchurian fruits may have retained their vitality over a period much exceeding four hundred years, possibly for thousands of years.

The sequence of events, as outlined by Chaney in The Garden Journal of the New York Botanical Garden, 1, No. 5, 137 (September 1951) and by Ohga, seems to have been as follows. On the floor of a lake, about a mile across, in the Pulantien Basin of southern Manchuria, there accumulated a thick layer of plant fragments, among them the durable fruits of the lotus, a species which grows in shallow water. This process may have taken several centuries. Later the lake drained, and dust from the Gobi desert covered the peat with several feet of loess. The Japanese geologist Endo believes this loess deposit to be of Pleistocene age and the peat layer and its fruits to be 50,000 years old; if so, these fruits may have begun their long sleep at a time when Peking man (Pithecanthropus pekinensis) roamed eastern Asia.

To botanists accustomed to the short period during which most seeds and fruits retain their vitality, Ohga's estimate of a longevity of four hundred years was startling; Endo's estimate of 50,000 years accordingly seems fantastic, although a form of packing which protected the embryo and its foodreserves against molecular change so effectively for four hundred years might well protect them indefinitely. There can be no doubt that these Manchurian lotus fruits are very old. The species nowadays does not grow wild within a thousand miles of the Pulantien lake, and these Pulantien fruits differ in size and shape from those of the modern Indian form of the species with which they have been compared. A preliminary investigation by Dr. W. F. Libby, University of Chicago, of the residual carbon-14 isotope of a few fruits available in the United States puts their age at 1,040 years $( \pm 210)$ according to a note in Science, 114, 296 (September 1951). Further investigation is planned.

The retention of viability by Nelumbo fruits for a thousand years or so is in its way as great a botanical sensation as the discovery of Metasequoia glyptostroboides a few years ago. 